\title{
Comparative Study of Boron Accumulation in Flag Leaf, Spike and Grain of Wheat (Triticum aestivum L.) Grown under Heat Stress
}

\author{
Satish Kumar ${ }^{1 *}$, Rajeev Kumar ${ }^{1}$, Pankaj Kumar ${ }^{1}$ and Santosh Kumar Singh ${ }^{2}$ \\ ${ }^{1}$ Department of Agricultural Biotechnology and Molecular Biology, ${ }^{2}$ Department of soil \\ science, DRPCAU, Pusa, Bihar-848125, India \\ *Corresponding author
}

\section{Keywords}

Wheat, micronutrient, Flag leaf, Spike, Booting and heat stress

Article Info

Accepted:

10 April 2018

Available Online:

10 May 2018

\section{A B S T R A C T}

Micronutrients are essential for human health and crucial for plant survival. Increasing temperature and heat are major abiotic stress which limits yield and nutritional quality of wheat. The objective of study is to evaluate the effect of heat stress on boron (B) micronutrient accumulation in 18 wheat varieties at three phenological stages (Booting and grain filling and maturity). Pot experiments were conducted in randomized block design with three replications during rabbi 2012-13 at DRPCAU, Pusa, Bihar. Results showed the accumulation of micronutrient under heat stress in booting, grain filling and maturity decreased significantly in flag leaf, spike and grain but some varieties enhances the accumulation of micronutrients under heat stress condition significantly. The wheat variety namely C306 (68.29 ppm), MB4010 (53.66 ppm), HD2888 (52.73 ppm), Iepacarabe (49.71ppm), AKAW4008 (41.16 ppm) and Kauz/AA/Kauz (40.73 ppm) are good accumulator of B in flag leaf and varieties F5-995 (75.50ppm), Sonalika (30.83ppm), MonsAld's (29.93 ppm) and Iepacarabe (21.73ppm) increases boron accumulation in spike under heat stress. The enhanced boron accumulation under high temperature in grain was observed in variety namely AKAW4008 (32.82ppm) and PBW343 (26.94 ppm) respectively. The wheat variety F5-995, PBW343 MonsAld's and AKAW4189-3 showed overall better micronutrients accumulation in flag leaf, spike and grain under stress condition and appeared as potentially important wheat variety used during heat stress.

\section{Introduction}

Wheat is one of the most important energy and nutrition sources of over growing world population. Wheat provide $21 \%$ food calories and $20 \%$ protein to more than 4.5 billion people worldwide and also consumed directly in different forms (Barun et al., 2010). High temperature is a major problem in agricultural cropping systems world-wide, with unexpected variations in temperature causing reduction in growth, development, metabolism and yield, with great risks for future global food security (Christensen and Christensen 2007; Parent et al., 2010). The optimum temperature for grain development of wheat varies between $15-18{ }^{\circ} \mathrm{C}$ (Chowdhury and Wardlaw, 1978; Modhej et al., 2011). Under heat stress Zong-hu and Rajaram (1994) reported that decline in number of spike per 
plant, grain number per spike and also reduction in grain weight.

Boron (B) is a member of the subgroup III of metalloids and has intermediate properties between metal and non-metals (Marschne, 1995). Despite its low abundance in nature, boron is widely distributed in lithosphere and hydrosphere, boron concentration ranging from 5-10 $\mathrm{mg} / \mathrm{kg}$ in rocks (Shorrokes, 1997), 3-30 microgram $/ \mathrm{kg}$ in rivers (Power and Woods, 1997) and approx.. 4.5mg/L in ocean (Lemarchand et al., 2000). Boron (B) is an essential element for plants and boron deficiency is the most widespread of all the micronutrient deficiencies in many crop regions from tropical to temperate zones (Shorrocks, 1997). Boron is required for flowering, cell wall formation, membrane integrity, carbohydrate utilization and stomatal conductance (Marschner, 1995) but vegetative growth of the plant is apparently unaffected by B deficiency (Mozafar, 1993). However, in many regions in the world $\mathrm{B}$ concentration in soilor irrigation water often exceeds plant requirements, thus becoming a threat to crop productivity (Nable et al., 1997). Thus in the field it is commonly observed that plants remained free of B deficiency symptoms until reproductive growth commences when a variety of B deficiency symptoms may appear including abortion of flower buds or flowers, male sterile flowers, aborted fruit and pots with reduced number of seeds and reduced seed size (Dell and Huang 1997; Huang et al., 2000). Under low rainfall conditions boron cannot be sufficiently leached and therefore may be accumulate to leaves that become toxic to plant growth (Reid, 2007a and b) and also induces oxidative stress, leaf chlorosis, necrosis, which reduce photosynthesis and dry matter accumulation. In wheat genotypes due to B deficiency, grain set failure associated with male sterility was observed in Brazil in 1962 (de Silva et al., 1980). Cheng and Rerkasem, 1993; Rerkasem, et al., 1993; Huang et al., 2000 reported that Boron deficiency cause grain set failure in wheat which is associated with poorly developed pollen and anthers. Jamjod et al., (2004) reported two genes, Bod 1 and Bod 2 that could account for genotypic variation in response to boron in wheat genotypes. The main goal of this study was to assess whether the greater boron accumulation such as in flag leaf, spike and grain compared with normal and heat stress.

\section{Materials and Methods}

\section{Plant material and growth conditions}

Plant material for micronutrients analysis studies of eighteen wheat variety namely AKAW4008, Halna, Pusa gold, AKAW41893, PBW343, HD2733, C306, HD2285, RSP561, Kauz/ AA/Kauz, Iepacarabe, F5-995, HD2888, MonsAld's, Kauz-dwarf, MB4010, Sonalika, and Raj3765 obtain from RKVY Project titled: Enhancement of heat tolerance in locally adapted wheat cultivars of Bihar" in department of Agricultural Biotechnology and Molecular Biology, DRPCAU, Pusa, Bihar. Seeds were washed in distilled water and sterilized by immersion in mercury dichloride solution $(1: 1000)$ for two minutes. The seed were next washed five times in deionizer water and placed in an oven at $28^{\circ} \mathrm{C}$ for 24 hours. After that the seeds were grown in greenhouse in $24 \times 21 \mathrm{~cm}$ pots containing soils. The experiment was conducted using 108 pots. 18 wheat varieties were sown in plastic pot using completely randomized design (CRD) in six replications. During the vegetative growth plant were kept under similar environment conditions. Half of the pots, three replications of each of the 18 wheat varieties were shifted under polyhouse condition to provide heat stress before booting. For each varieties 6 replication were used (Three heat stress and three in natural condition). During the period of experiment the position of the pot was changed weekly, to minimize the effects due to irradiance 
variations. Plants were irrigated weekly to1/2 Hoagland solution as per schedule and requirement. Maximum and minimum temperatures $\left({ }^{0} \mathrm{C}\right)$ as well as relative humidity (\%) were recorded during the crop growth period. The minimum $\left(6.5^{\circ} \mathrm{C}\right)$ and maximum $\left(38.9^{\circ} \mathrm{C}\right)$ temperature recorded in open condition. Polyhouse minimum $\left(10.4{ }^{\circ} \mathrm{C}\right)$ and maximum $\left(45.23^{\circ} \mathrm{C}\right)$ temperature recorded.

\section{Sample preparation and nutrient analysis}

The concentration of Boron was determined at three phenological stages as booting (flag leaf), grain filling (spike) and maturity (grain) of control and stressed plants. The plant samples were washed with $0.2 \%$ liquid detergent (The liquid detergent removes waxy coating of the leaf surface and any soil particle) solution, than with $0.1 \mathrm{~N} \mathrm{HCl}$ solution $(0.1 \mathrm{~N} \mathrm{HCl}$ removes metallic contaminants) and finally with deionized water (Deionized water washes the previous two solutions). After that the extra moisture was wiped out, the sample was placed in new paper bags and dried in an oven at $70^{\circ} \mathrm{C}$. Plant samples were digested following the methods given by Hatcher and Wilcox (1950). 0.5g oven dried sample was digested in diacid mixture (HNO3:HClO4, 10:4) on a rectangular hot plate. After the completion of the digestion the colour become milky white. It was filtered through Whatman filter paper and volume was made up to $50 \mathrm{ml}$ by adding double distilled water. After that $2 \mathrm{ml}$ aliquot was taken in conical flask and 1-2 drop $\mathrm{NHCl}$ and $10 \mathrm{ml}$ conc. $\mathrm{H}_{2} \mathrm{SO}_{4}$ was added to it after cooling 15 $\mathrm{ml} 0.05 \%$ carmine solution was added to it. After 45 minutes, intensity of colour was measured in photoelectric colorimeter at 585 $\mathrm{nm}$ wave length and data were recorded.

\section{Statistical analyses}

Graph and Two-way Analysis of Variance (ANOVA) was carried out using graph pad prism statistical software version 5.01. Values presented were means \pm standard error (SE) of three replicates in each group. $P$-values $\leq 0.05$ were considered as significant.

\section{Results and Discussion}

Temperature and nutrition are two of the major components of environmental variation, and together provide significant limitations to successful crop production. Increasing temperatures during developmental stage disturb metabolism, growth and reproduction in plant. Elevated temperature affects the micronutrient accumulation in flag leaf, spike and grain of (Triticum aetivum L.) variety at three phonological stages (booting, grain filling and maturity). Analysis of Boron was done in flag leaf, spike and seeds obtained from three phenological stages respectively of 18 varieties of wheat grown under two conditions i.e. normal and heat stress. The data regarding boron content revealed that boron content significantly decreased under heat stress as compared to normal condition but in severely-stressed plants, levels of B increased in compression to unheated plant. Among wheat genotypes C306 (68.29 ppm) recorded significantly highest $\mathrm{B}$ content in flag leaf under high temperature followed by MB4010 (53.66 ppm), HD2888 (52.73 ppm), Iepacarabe (49.71 ppm), AKAW4008 (41.16 ppm) and Kauz/AA/Kauz (40.73 ppm). Marschner (1995) observed that the amounts of B required for seed formation are generally greater than those required for vegetative growth. Varieties namely Halna, Pusa gold, AKAW4189-3, HD2733, HD2285, RSP561, Iepacarabe, F5-995, MonsAld's, Sonalika, and Raj3765 have accumulated significantly more boron in flag leaf under normal condition. Abdel-Motagally and El-Zohri, (2016) also reported that improvement of wheat yield grown under drought stress by boron foliar application at different growth stages such as booting and grain filling stage (Fig. 1). 


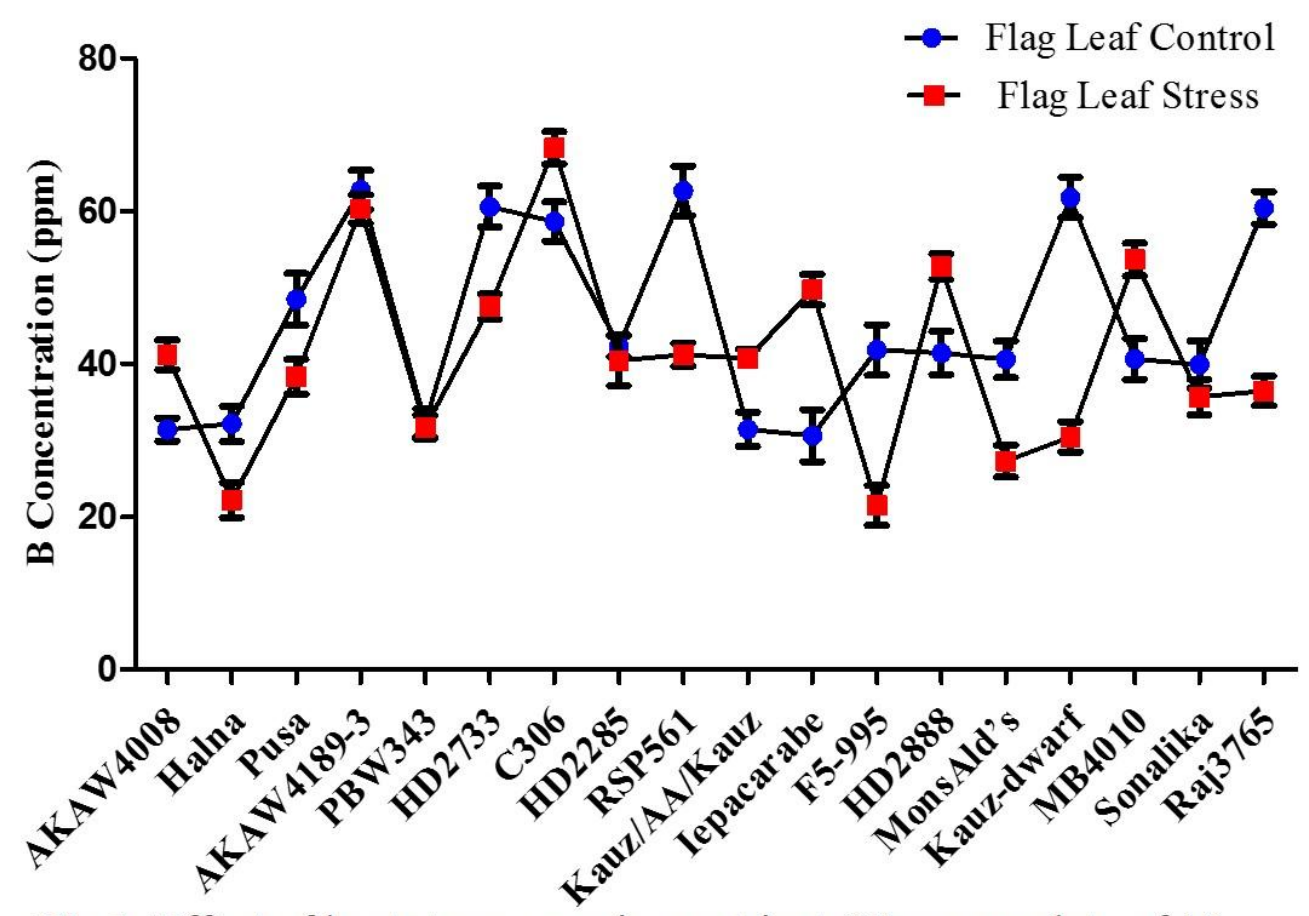

Fig.1. Effect of heat stress on micronutrient (B) accumulate of 18 wheat varieties under control and stress flag leaf

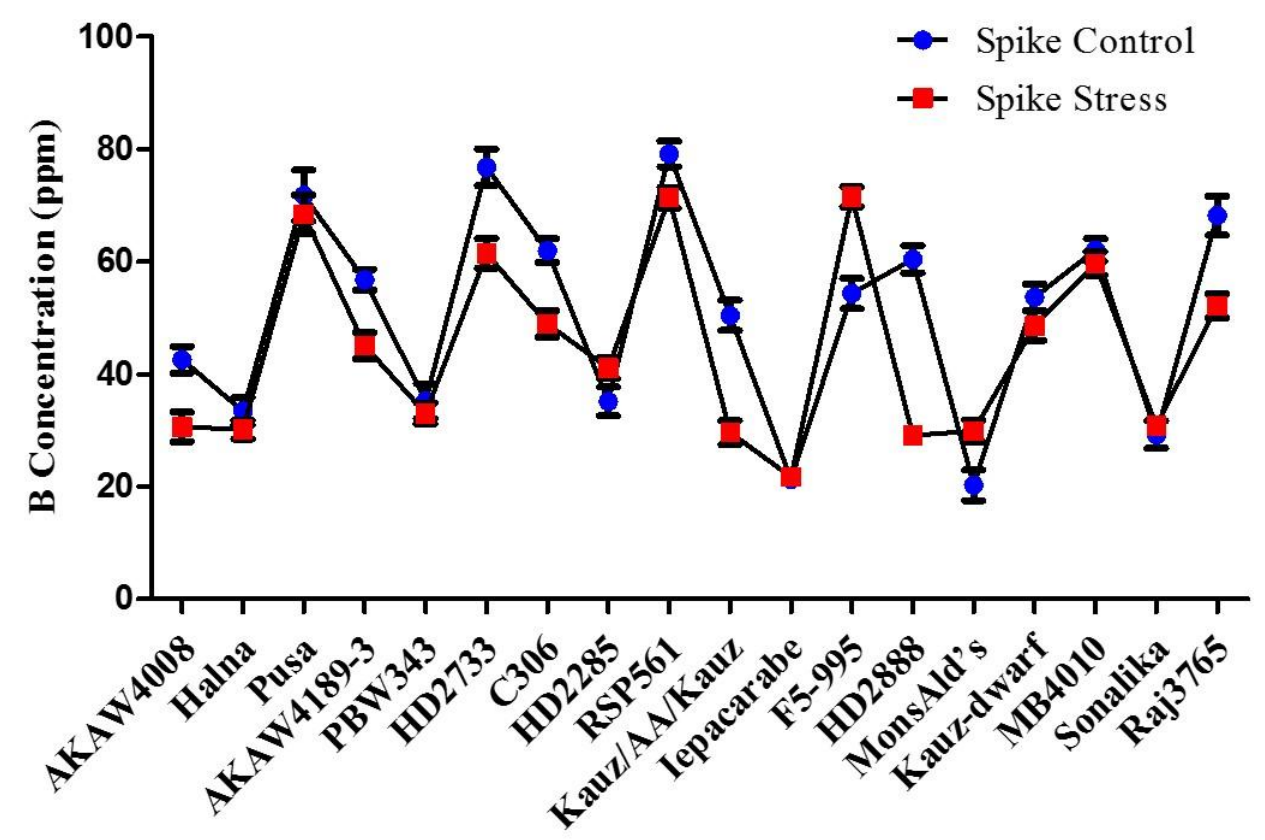

Fig.2. Effect of heat stress on micronutrient (B) accumulate of 18 wheat varieties under control and stress spike 


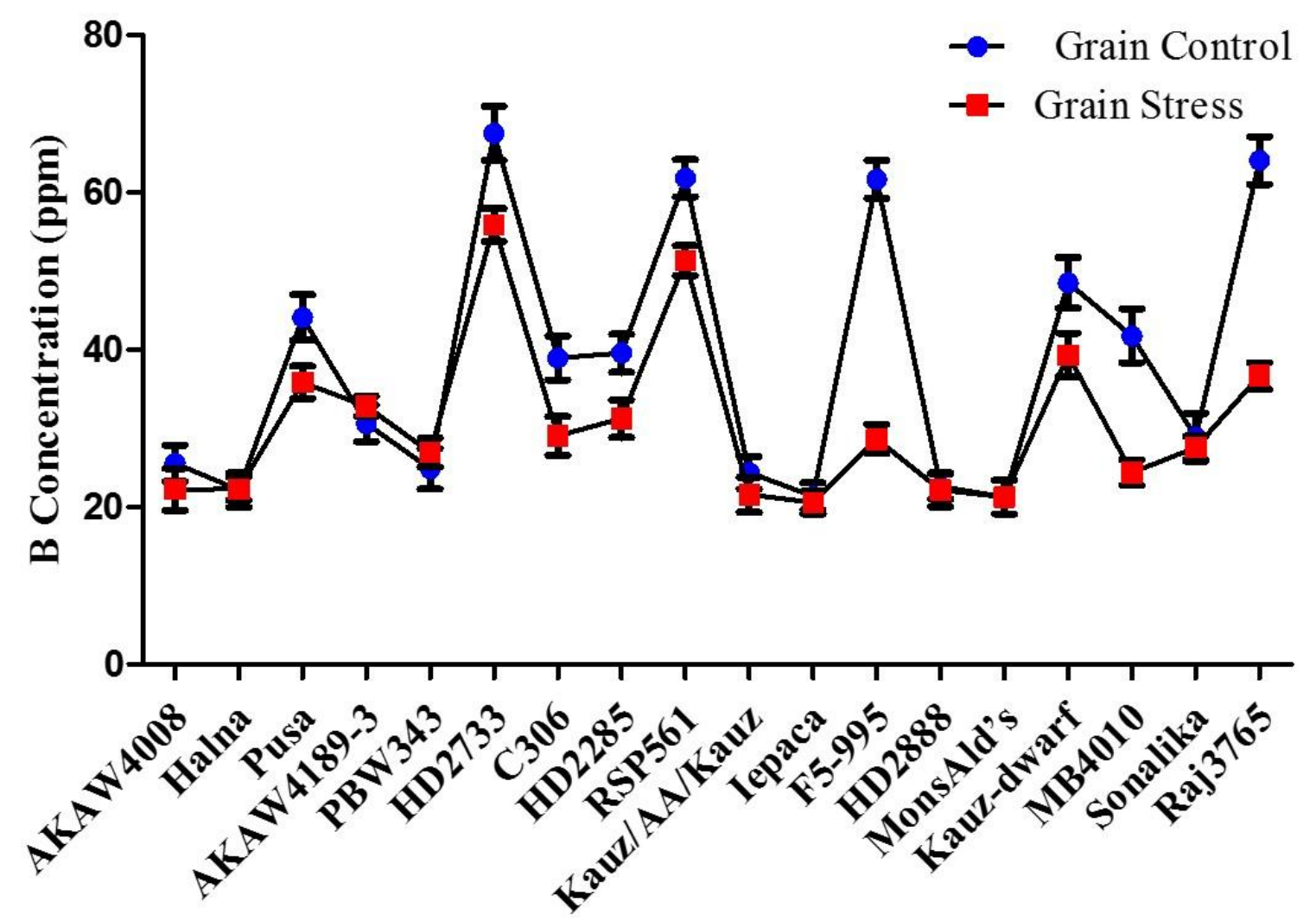

Fig.3. Effect of heat stress on micronutrient (B) accumulate of 18 wheat varieties under control and stress grain

Despite the fact that wheat is grown as a winter season crop in India, the occurrence of heat stress (maximum daily temperatures above $35^{\circ} \mathrm{C}$ ) is a frequent phenomenon across the India wheat belt during the growing season, particularly during the grain filling period (Blumenthal et al., 1995).

As depicted in figure 2, boron content significantly increases in spike under heat stress up to $(75.50,30.83,29.93,21.73 \mathrm{ppm})$ in varieties namely F5-995 Sonalika, MonsAld's and Iepacarabe respectively. The remaining varieties namely AKAW4008, Halna, Pusa gold, AKAW4189-3, PBW343, HD2733, C306, HD2285 RSP561, Kauz/ AA/Kauz, HD2888, Kauz-dwarf, Raj3765and MB4010 there have been reduced $B$ accumulation significantly under high temperature in compression to normal condition.

Deficiency of boron leads to reduced flowering and grain filling stage produce less number of seeds in spike. Figure 3 represents the mean value and SE the accumulation of $B$ under heat stress significantly increased in seeds in two variety AKAW4008 (32.82ppm) and PBW343 (26.94 ppm). Arif et al., (2006) observed that the enhanced wheat crop yield by B spraying at booting stage may be due to provision of $\mathrm{B}$ at initial stages which might have enhanced the accumulation of assimilate in the grains. Velu et al., (2016) also reported the amount of $\mathrm{Fe}$ and $\mathrm{Zn}$ increased in grain of PBW 343 wheat variety under elevated 
temperature. Not more studies were carried out to examine the effect of boron and climatic changes in wheat genotypes. The overall results showed that boron accumulation in flag leaves faster than the spike and grain under heat stress. The wheat variety F5-995, PBW343 MonsAld's and AKAW4189-3 showed overall better micronutrients accumulation in flag leaf, spike and grain under stress condition and appeared as potentially important wheat variety used in plant breeding for production of heat stress variety.

\section{Acknowledgment}

The authors are thankful to DBT for providing financial support in the form of Research Fellowship during the course of my study and provide fund for my research work. We would like to thanks Dr. V. K. Shahi Dean of FBS\&H PUSA and all faculty members of $\mathrm{AB} \& \mathrm{MB}$ for their support during this research work.

\section{References}

Abdel-Motagally, F. M. F. and El-Zohri, M. (2016). Improvement of wheat yield grown under drought stress by boron foliar application at different growth stages. Journal of the Saudi Society of Agricultural Sciences.

Arif, M., Chohan, M. A., Ali, S., Gul, R. and Khan, S. (2006). Response of wheat to foliar application of nutrients. Journal of Agricultural and Biological Science, 1(4), 30-34.

Blumenthal, C., Bekes, F., Gras, P. W., Barlow, E. W. R. and Wrigley, C. W. (1995). Identification of wheat genotypes tolerant to the effects of heat stress on grain quality. Cereal chemistry.

Braun, H.-J., Atlin, G. and Payne, T. (2010). Multi-location testing as a tool to identify plant response to global climate change. Climate change and crop production, 1, 115-138.

Cheng, C. and Rerkasem, B. (1993). Effects of boron on pollen viability in wheat. Plant and soil, 155(1), 313-315

Chowdhury, S. I. and Wardlaw, I. F. (1978). The effect of temperature on kernel development in cereals. Australian Journal of Agricultural Research, 29(2), 205-223.

Christensen, J. H. and Christensen, O. B. s. (2007). A summary of the PRUDENCE model projections of changes in European climate by the end of this century. Climatic change, 81(1), 7-30.

Da Silva, A. R. and de Andrade, J. M. V. (1980). A cultura do trigonasvarzeas de Minas Gerais-possibilidades e dificuldades. Embrapa, Centro de PesquisaAgropecu $\tilde{A}_{i}$ ria dos Cerrados (CPAC). Circular TÃ@cnica(2), 69

Dell, B. and Huang, L. (1997). Physiological response of plants to low boron. Plant and soil, 193(1-2), 103-120.

Hatcher, J. T. and Wilcox, L. V. (1950). Colorimetric determination of boron using carmine. Analytical chemistry, 22(4), 567-569.

Hoagland, D. R. and Arnon, D. I. (1950). The water-culture method for growing plants without soil. Circular. California agricultural experiment station, 347(2nd edit).

Huang, L., Pant, J., Dell, B. and Bell, R. W. (2000). Effects of boron deficiency on anther development and floret fertility in wheat (Triticum aestivum L. â€ Wilgoyneâ€ $\left.€^{\mathrm{TM}}\right)$. Annals of Botany, 85(4), 493-500.

Jamjod, S., Niruntrayagul, S. and Rerkasem, B. (2004). Genetic control of boron efficiency in wheat (Triticum aestivum L.). Euphytica, 135(1), 21-27.

Lemarchand, D., Gaillardet, J., Lewin, E. and Allegre, C. J. (2000). The influence of 
rivers on marine boron isotopes and implications for reconstructing past ocean pH. Nature, 408(6815), 951.

Marschner, H. (1995). Mineral nutrition of higher plants. 2nd (eds) Academic Press. New York.

Modhej, A., Naderi, A., Emam, Y., Aynehband, A., Normohamadi, G. and Kaivan, E. (2011). Evaluation of the effects of post-anthesis heat stress and nitrogen levels on grain yield and grain growth of wheat genotypes under Khuzestan conditions. Agronomy Journal.

Mozafar, A. (1993). Role of boron in seed production. Boron and its Role in Crop Production. Ed. UC Gupta, 186-206

Nable, R. O., Banuelos, G. S. and Paull, J. G. (1997). Boron toxicity. Plant and soil, 193(1-2), 181-198.

Parent, B., Turc, O., Gibon, Y., Stitt, M. and Tardieu, F. (2010). Modelling temperature-compensated physiological rates, based on the co-ordination of responses to temperature of developmental processes. Journal of Experimental Botany, 61(8), 2057-2069

Power, P. P. and Woods, W. G. (1997). The chemistry of boron and its speciation in plants. Plant and soil, 193(1-2), 1-13.

Reid, R. (2007a). Identification of boron transporter genes likely to be responsible for tolerance to boron toxicity in wheat and barley. Plant and cell physiology, 48(12), 1673-1678.

Reid, R. (2007b). Update on boron toxicity and tolerance in plants. Advances in plant and animal boron nutrition. Springer, Dordrecht, The Netherlands, 83-90.

Rerkasem, B., Netsangtip, R., Lordkaew, S. and Cheng, C. (1993). Grain set failure in boron deficient wheat. Plant and soil, 155(1), 309-312.

Shorrocks, V. M. (1997). The occurrence and correction of boron deficiency. Plant and soil, 193(1-2), 121-148.

Velu, G., Guzman, C., Mondal, S., Autrique, J. E., Huerta, J. and Singh, R. P. (2016). Effect of drought and elevated temperature on grain zinc and iron concentrations in CIMMYT spring wheat. Journal of Cereal Science, 69, 182-186

Wardlaw, I. F., Dawson, I. A. and Munibi, P. (1989). The tolerance of wheat to high temperatures during reproductive growth. 2. Grain development. Australian Journal of Agricultural Research, 40(1), 15-24.

Zhong-hu, H. and Rajaram, S. (1993). Differential responses of bread wheat characters to high temperature. Euphytica, 72(3), 197-203

\section{How to cite this article:}

Satish Kumar, Rajeev Kumar, Pankaj Kumar and Santosh Kumar Singh. 2018. Comparative Study of Boron Accumulation in Flag leaf, Spike and Grain of Wheat (Triticum aestivum L.) Grown under Heat Stress. Int.J.Curr.Microbiol.App.Sci. 7(05): 905-911. doi: https://doi.org/10.20546/ijcmas.2018.705.110 